\title{
Reef
}

\section{Chance encounter.}

$\mathrm{O}$ nly Sam's inner ear told her that she was drifting slowly downwards; the slate-green ice walls of the borehole were completely uniform and offered no visual cues of motion. She selected downward thrust to speed up a bit.

"Selection denied," said the suit's autopilot. "Early use of battery resources inadvisable."

Speeding up would bring her back onto the mission profile and restore lost time. Once under the ice she could drift to compensate for the extra energy used on the way down. But the bureaucrats of the World Space Authority were very risk adverse and their autopilot was having none of it.

"Abort?" it asked.

The abort option presented automatically whenever a selection was refused. She selected 'no' and drifted downwards as patiently as she could. Eventually the walls disappeared, to be replaced by a vaulted ceiling sprinkled with glittering reefs rooted in ice. Her searchlights returned coloured

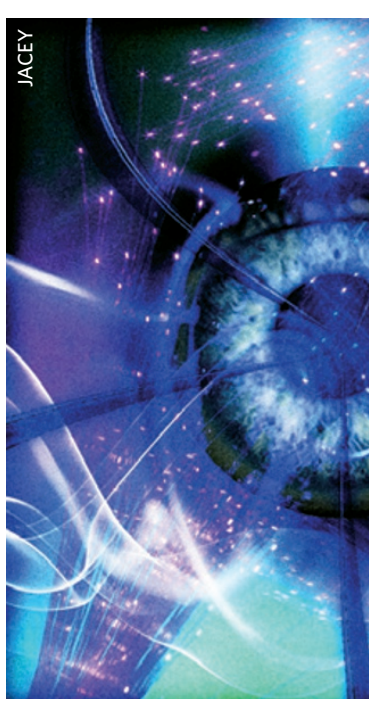

for the Change. It could hardly believe its luck; most lived long lives and died without Changing. To Change was to embark on the ultimate meditation, to become part of the universal nothingness.

There was someone between it and the source, swimming clumsily. A Rival! Cheerth's joy increased. Success after righteous struggle brings bliss. Cheerth swept in.

The Rival was smaller and was like no creature Cheerth had ever seen or heard of. It was swimming away from the source of manna so it was either confused or not very bright. But it was trailing the longest sting that Cheerth had ever seen, so long that the end disappeared into the distance. Strange.

Merit comes

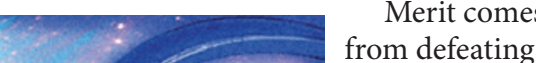
from defeating a rival without injuring it. But a sting can easily be regrown. Strange challenges may require strange responses.

Sam saw it before the suit's sensors did, a rhythmic movement rising from the depths. She turned off the thrusters and watched. The thing looked like the front half reflections, a display of cold fireworks for the billions watching through the cable that linked her to the lander on Europa's surface. The bottom was too far down to see.

Cheerth was meditating, emptying its mind of thoughts, approaching the great emptiness, when it sensed a taste so rich it could not be ignored, could barely be believed - manna that was much stronger than the thin streams that occasionally appeared leaking from deep cracks. Cheerth abandoned the meditation and swam up from the placid depths into the

\section{$\rightarrow$ NATURE.COM}

Follow Futures: y @NatureFutures f go.nature.com/ mtoodm tide-swept bubble of water that reached almost to the surface, feeling hormones rushing through its body, preparing it of a squid joined to the bell-shaped body of a jellyfish. Four equally spaced tentacles sprouted from its side. It was coming straight towards her. Towards her!

She selected full power.

"Ramping up to full power to avoid excess motor wear," said the autopilot. "Full

A little graphic appeared showing the current throttle setting as it crept towards full.

There was no override. All Sam could do was watch as the creature approached.

"It's about $50 \%$ bigger than I am." It was much nearer now. "There is a line of white circles around the tip that could be vibration receptors. It can sure as hell see me."

Her voice was going all the way back to Earth as well as to Ceres base. She might be seeing things that the video was missing. power in 45 seconds."
"Oh shit."

It was on her. She threw up her hands as if to ward it off and it surged past.

An alarm sounded and a red light flashed.

"Critical malfunction," said the autopilot.

"Umbilical severed. Abort selected."

The monster was above her, heading for the borehole. She was doomed.

"The abort routine is taking me straight towards the thing," said Sam. "Provide an abort override next time. Goodbye and don't give up."

The sting had been like no other. It had been immensely tough: it had cut right through two tentacles before Cheerth had severed it with a third. But tentacles didn't matter anymore.

Nothing did. Ecstasy was coursing through Cheerth as its anchor began to form. Its mind began to empty and it began to develop sex organs. A future without desire or pain beckoned. S/he was dimly aware that the Rival was approaching. Surely it did not want a rematch? Its four stubby tentacles were not much of a threat. Cheerth could easily snap them off. Yet this was a worthy Rival that had waved Cheerth on, offering to duel with its sting. Compassion in victory brings merit.

Cheerth tried to focus; the effort was harder than fasting for a full cycle. So strange to be groping to form a thought after a lifetime of learning to let them pass by. Slowly s/he moved to one side to allow the defeated opponent a place to anchor near the strange circular crack. The Rival swam towards Cheerth, getting faster as it approached and coming much too close. Cheerth swept out a tentacle to push it aside. It twisted past and entered the crack as if drawn by the powerful manna streaming down. Cheerth cried after it but it ignored him/her and swam upwards to certain death on the surface.

Cheerth extended gamete sacs into the manna where they would become fertile. Thoughts of the brave, doomed Rival, of offspring, and even of the bliss of approaching nothingness faded as his/her brain melted away and s/he hardened into the nucleus of a reef.

JOHN FRIZELL was trained in biochemistry and works in ocean conservation for Greenpeace. In his spare time he walks, builds robots and sings. 